\title{
Photocatalytic Properties of Transparent ZnO Films Prepared by Anodization of Zinc Plate
}

\author{
Sawako KUSAKARI*, Kensaku SHINOZAKI, Kazuya HiGA, \\ Yasuhide YAMAGUCHI ${ }^{\dagger}$, Sachio YOSHIHARA and Takashi SHIRAKASHI
}

Received December 26, 1997 ; Accepted March 4, 1998

\begin{abstract}
Transparent zinc oxide films were prepared by anodizing of a zinc plate when the electrolyte was kept at low temperature $\left(<10^{\circ} \mathrm{C}\right)$ in low concentration of alkaline solution and under high bias voltage. Obtained transparent film was uniform, and it showed transparency even if it might be thick. Thus obtained transparent film is confirmed to be a pure zinc oxide, and its absorption edge is $380 \mathrm{~nm}$, which corresponds to the optical bandgap energy of $3.2 \mathrm{eV}$. Moreover, it had high photocatalytic activity which was superior to the one prepared under no cooling. We have already reported that the photocatalytic properties were closely correlated with their orientation preference of (1010) face. In this case, thus obtained transparent film also showed preferred orientation of the $(10 \overline{10})$.
\end{abstract}

\section{INTRODUCTION}

Zinc oxide $(\mathrm{ZnO})$ is an oxide semiconductor that has the bandgap energy of $3.2 \mathrm{eV}$. ${ }^{1)}$ Such a wide bandgap semiconductor could be available for highly oxidizing photocatalyst like a titanium dioxide. When $\mathrm{ZnO}$ absorbs a light energy greater than its bandgap energy, excited electron-hole pairs bring about oxidation-reduction reaction. So, it is well-known that $\mathrm{ZnO}$ could be applicable as a photocatalyst. ${ }^{1)}$ Therefore, there were many reports about photocatalytic properties of $\mathrm{ZnO} .^{2-5)}$ It was reported that the $\mathrm{ZnO}$ films could be prepared simply by anodizing of a zinc

Department of Applied Chemistry, Faculty of Engineering, Utsunomiya University (2753, Ishii-machi, Utsunomiya, Tochigi, 321-8585, Japan)

' MITSUI KINZOKU R\&D Center (1333-2, Haraichi, Ageo, Saitama, 362-0021, Japan)

Key Words : Zinc oxide, Transparent, Anodizing, Photocatalyst plate in sodium hydroxide (NaOH) aqueous solution, the prepared films showed white color or black color depending on its preparation conditions such as the electrolyte concentration (0.1-0.5 mol $\mathrm{dm}^{-3}$ ) or the anodizing voltage $(5-30 \mathrm{~V}){ }^{6)}$ And the photocatalytic activity of anodized films was also different depending on its preparation conditions. ${ }^{1)}$ In addition, Izaki et al. have reported that transparent and conductive $\mathrm{ZnO}$ films could be formed by electrodeposition 7) and chemical preparation ${ }^{8)}$ from a zinc nitrate aqueous solution. However, the effect of the electrolyte temperature during anodizing was not studied before. We succeeded in obtaining a transparent and efficient $\mathrm{ZnO}$ film photocatalyst by anodizing at low temperature. So in this paper, we report the morphology and photocatalytic activity of the $\mathrm{ZnO}$ films formed by anodization of zinc plate under low temperature. 


\section{EXPERIMENTAL}

2.1 Preparation of zinc oxide films by anodizing

A rolled zinc sheet (purity $>99.99 \%$, $60 \times 50 \times 0.5 \mathrm{~mm}^{3}$ ) was used as the substrate for anodizing, and the surface was cleaned by a degreasing agent (Mitsui Kinzoku AZ302), which consists of alkaline salts and nonionic surfactants, followed by washing in distilled water. This zinc sheet was covered with a sticky plastic tape except for the anode surface. A stainless steel (SUS 304) plate was used as a cathode. These electrodes were placed at a distance of $50 \mathrm{~mm}$. The electrolytes used for anodizing were various concentrations of $\mathrm{NaOH}$ aqueous solutions $\left(0.1 \cdot 0.5 \mathrm{~mol} \mathrm{\textrm {dm } ^ { - 3 }}\right)$, whose volume was $1 \mathrm{dm}^{3}$.

A DC voltage $(5,20$, and $30 \mathrm{~V})$ was applied for $20 \mathrm{~min}$. to both electrodes. Anodized zinc films were washed in distilled water, followed by drying in a flow of cold air.

Moreover, under cooling the electrolyte $\mathrm{ZnO}$ films were prepared similarly. The inner electrolysis bath was surrounded by ethanol cold outer bath which was cooled by immersion cooler (EYELA ECS-0).

\subsection{Photocatalytic activity test}

The photocatalytic activity was evaluated by measuring the decomposition rate of acetaldehyde gas. The chamber for photocatalytic test was illustrated in Fig.1. The chamber was made of a hard glass (volume $144 \mathrm{~cm}^{2}$ ) with a quartz glass window. And complete sealing was accomplished by PARAFILM. Acetaldehyde gas was introduced to the chamber. The initial concentration of acetaldehyde was controlled to ca. 100 ppm. The black lights $(10 \mathrm{~W} \times 5)$ illuminated the substrate through a quartz glass window, and then the UV
Black light $(10 W \times 5)$

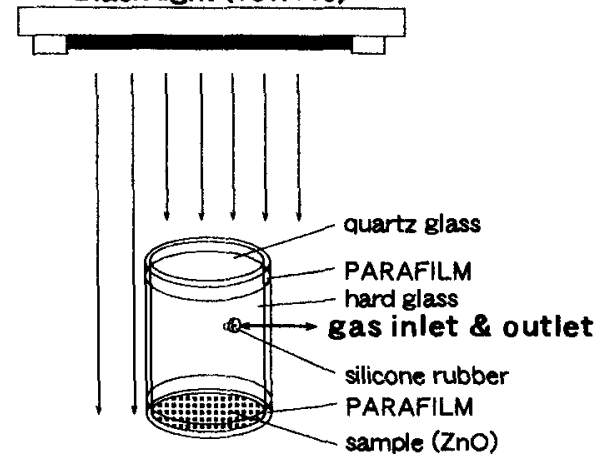

Fig.1 Experimental apparatus for photocatalytic tests.

light intensity on the film was $0.18 \mathrm{~mW}$ $\mathrm{cm}^{-2}$. Thereafter, the concentration change of the inner gas with time was monitored by gas chromatography. The gas was sampled by a microsyringe $(10 \mu \mathrm{l})$. A gas chromatograph (Shimadzu GC-14B) equipped with a flame ionization detector (FID) and a capillary column ( $\mathrm{H} \& \mathrm{~W}$ Scientific DB-WAX) was used for the quantitative analysis of acetaldehyde.

\section{RESULTS AND DISCUSSION}

\subsection{Electrolytic condition and} morphology of anodized films

Prepared films showed white or black color depending on its preparation conditions, when zinc plates were anodized at room temperature without using cold bath. White film could be prepared under low concentration of alkaline electrolyte $\left(0.1,0.2 \mathrm{~mol} \mathrm{dm}^{-3}\right)$ and high applied voltage $(20,30 \mathrm{~V})$, on the other hand the black film could be prepared under low applied voltage. ${ }^{6)}$ The initial electrolyte temperature was equal to room temperature, ca. $20^{\circ} \mathrm{C}$. In the case of higher concentration of alkaline solution and higher applied voltage, the temperature of the bath was raised rapidly. For example in the case of 0.3 mol $\mathrm{dm}^{-3} \mathrm{NaOH}$ solution, $30 \mathrm{~V}$ applied 
voltage, the temperature was finally raised to $62^{\circ} \mathrm{C}$.

On the other hand, when the electrolyte was cooled with using cold bath, the initial temperature of the electrolyte was set at $0^{\circ} \mathrm{C}$, moreover, temperature rise during the electrolysis could be held below $10^{\circ} \mathrm{C}$. In this case, the color variation of the film was different from the one prepared under no cooling. Obtained film anodized at low applied voltage $(5 \mathrm{~V})$ under cooling showed black color. This tendency is similar to the one oxidized under no cooling. On the other hand, the one anodized at high bias voltage and in low concentration of alkaline solution showed transparency. Such a transparent films could be obtained only by cooling the electrolyte for anodizing.

Figure 2 shows the diffuse reflectance spectra for white, black, and transparent $\mathrm{ZnO}$ films. The absorption edge for three films is $380 \mathrm{~nm}$, which corresponds to the optical bandgap energy $(3.2 \mathrm{eV})$ of zinc oxide. With respect to transparent film, the spectrum showed fringe which was attributed to the interference. The film thickness calculated from this fringe was approximately the same as that estimated by cross sectional scanning electron microscope (ca. $2 \mu \mathrm{m}$ ). Therefore, it was found that thus obtained transparent zinc oxide film had fine structure and uniform thickness. The film prepared by anodizing for 60 min., (thickness : ca. $5 \mu \mathrm{m}$ ) showed also transparency. Compared with the

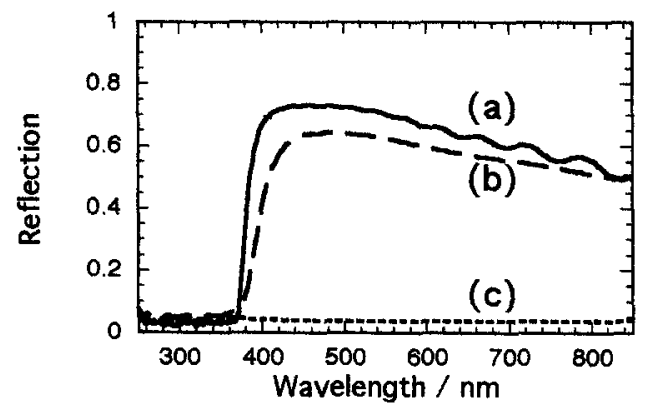

Fig. 2 Reflection spectra of anodized zinc plate; (a) Transparent $\left(0.1 \mathrm{~mol} \mathrm{dm}^{3}, 20 \mathrm{~V}\right.$, cooling), (b) White $\left(0.1 \mathrm{~mol} \mathrm{dm}^{-3}, 30 \mathrm{~V}\right.$, no cooling), and (c) Black ( $0.1 \mathrm{~mol} \mathrm{dm}^{-3}, 5 \mathrm{~V}$, no cooling).

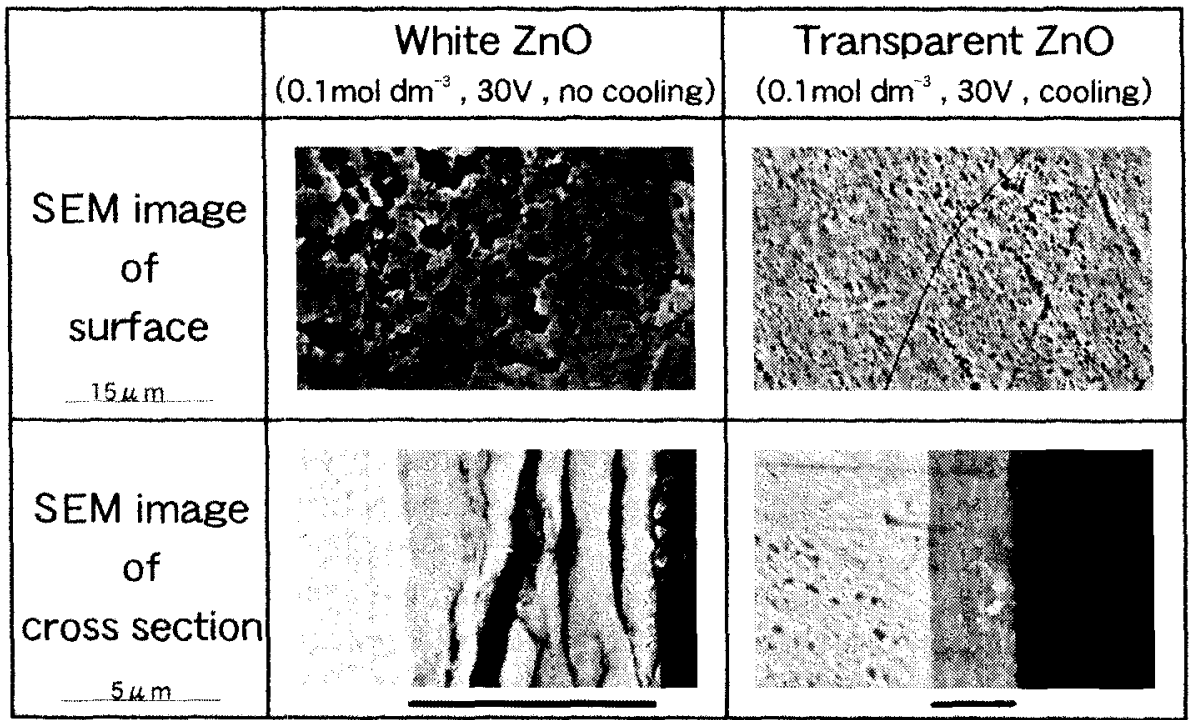

Anodizing time : $20 \mathrm{~min}$.

Fig.3 SEM images of surface and cross section of anodized zinc plate. 
transparent film cited in Fig.2 (thickness : ca. $3 \mu \mathrm{m}$ ), they showed little difference to the naked eye.

Figure 3 shows SEM images of the surface and cross section of the white

(prepared under no cooling) and transparent (prepared under cooling) films anodized in $0.1 \mathrm{~mol} \mathrm{dm}^{-3}$ solution under bias voltage $30 \mathrm{~V}$. The white film has a quite rough surface. Numerous pits (dia. ca. $3 \mu \mathrm{m}$ ) were observed on the surface. While the transparent film has relatively smooth surface and numerous smaller pits (dia. ca. $0.5 \mu \mathrm{m}$ ) were observed on the surface. These pits on the surface could be ascribed to the generation of oxygen gas. It was confirmed by the SEM image of cross section that white film involved inner crack, and consequently, it looks like a accumulated flake structure, while the transparent film has no inner crack and fine grain structure.

The weight change during anodization was measured by using quartz crystal microbalance (QCM). The results were shown in Fig.4. We already reported that the growth process of white film was quite different from that of black film. In this work, comparing frequency change obtained for the growth process of transparent film to one for white film, the growth rate for white or transparent films was 20 or $78 \mu \mathrm{g} \mathrm{min}^{-1}$, respectively, in $0.1 \mathrm{~mol} \mathrm{dm}^{-3}$ under $30 \mathrm{~V}$. The results of this study showed that the growth rate of the transparent film was relatively lower than that of white film.

When the QCM was employed in 0.1 mol $\mathrm{dm}^{-3}$ under $30 \mathrm{~V}$ under no cooling, the initial current was about $30 \mathrm{~mA} \mathrm{~cm}{ }^{-2}$ and a great deal of gaseous oxygen were evolved. But under cooling in the same condition, the initial current was nearly $22 \mathrm{~mA} \mathrm{~cm}^{-2}$ and the gas generation was inhibited under cooling. This show growth rate makes the fine and uniform structure of transparent zinc oxide.

\subsection{Photocatalytic tests}

Figure 5 shows the photocatalytic tests for white, black, and transparent films. The initial concentration of the acetaldehyde gas in the chamber was $c a$. $100 \mathrm{ppm}$, the photocatalytic activity of these films were evaluated by measuring the concentration change of acetaldehyde as a function of irradiation time under illumination of black light. For the films prepared in the same electrolytic condition $\left(0.1 \mathrm{~mol} \mathrm{dm}^{-3}, 30 \mathrm{~V}\right)$ except for

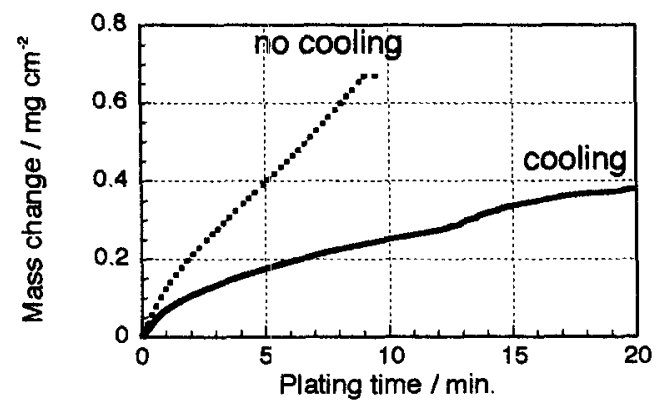

Fig. 4 The mass change monitoring of zinc anodization by $\mathrm{QCM}\left(0.1 \mathrm{~mol} \mathrm{dm}^{-3}, 30 \mathrm{~V}\right)$.

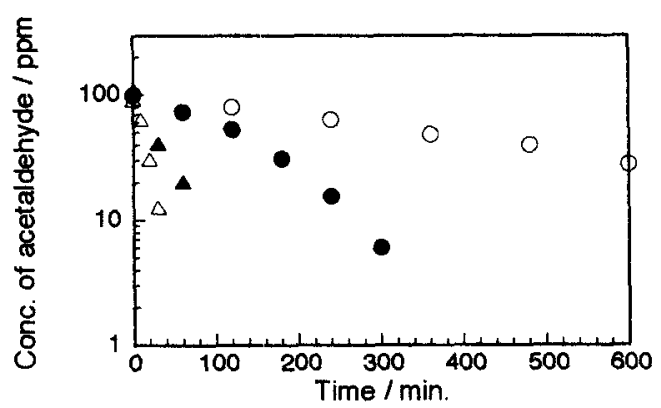

Fig. 5 Time dependence of the concentration of acetaldehyde gas remaining in the chamber under jllumination of black light. : $0.1 \mathrm{~mol} \mathrm{dm}^{-3} \mathrm{NaOH}, 5 \mathrm{~V} \mathrm{DC}$, no cooling (black)

$\bigcirc: 0.1 \mathrm{~mol} \mathrm{dm}^{-3} \mathrm{NaOH}, 5 \mathrm{~V} \mathrm{DC}$, cooling (black)

: $: 0.1 \mathrm{~mol} \mathrm{dm}^{-3} \mathrm{NaOH}, 30 \mathrm{~V} \mathrm{DC}$, no cooling

$\triangle: 0.1 \mathrm{~mol} \mathrm{dm}^{-3} \mathrm{NaOH}, 30 \mathrm{~V} D C$, cooling (transparent) 
the temperature of the electrolyte, the activity of the transparent film (cooling) was superior to that of the white film (no cooling), while that of the black film (0.1 mol dm $\mathrm{dm}^{-3}, 5 \mathrm{~V}$, obtained under cooling) was inferior to that of the black film obtained under no cooling in the same electrolysis condition.

Figure 6 shows the relationship between the prepared condition for films and the photocatalytic activity. The indicated values and diameter of the circles in Fig. 6 express the decomposition rates of acetaldehyde $\left(t_{1 / 10}{ }^{-1}\right)$, which are expressed by the reciprocal of time that the concentration of acetaldehyde decreases to one-tenth of its initial one. This result indicates that the activity of almost transparent films prepared under cooling was superior to that of white films prepared under no cooling.

Figure 7 shows the relationship between the decomposition rate and the thickness of films. The thickness of the film was controlled by varying its anodizing period, and it was confirmed by cross-sectional SEM image. As shown in Fig. 7, it is clear that the decomposition rate is higher as the thickness becomes

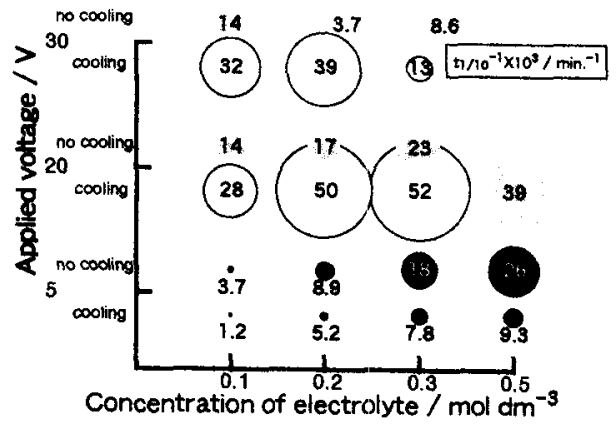

Fig. 6 The dimensional drawing of the photocatalytic activity as a function of $\mathrm{NaOH}$ concentration and applied voltage. Dimensions of the circles and digits show the decomposition rates of acetaldehyde; (O) Black, (Ф) White, and $(O)$ Transparent. larger, but the photocatalytic activity showed the saturation when the film thickness became larger than $1 \mu \mathrm{m}$.

It was already reported that the anodized zinc films, even if the color of the film was white or black, were the zinc oxide single phase. ${ }^{6)}$ Similarly, the transparent films in this study were also confirmed to be a zinc oxide single phase by XRD. We also have already reported that the photocatalytic activity was closely correlated with the orientation preference of (1010) face. ${ }^{1)}$ Also in this case (under cooling) we investigated the relationship between the decomposition rate and the XRD peak intensity ratio of

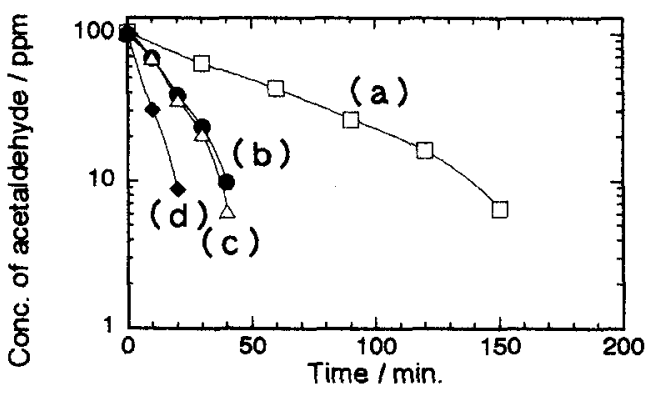

Fig.7 The relationship between the decomposition rates and the thickness of films. Anodizing time (thickness); (a) $1 \mathrm{~min}$. ( $<0.5 \mu \mathrm{m}$ ), (b) $5 \mathrm{~min}$. ( $1 \mu \mathrm{m}$ ), (c) 20min. ( 3 $\mu \mathrm{m})$, (d) $60 \mathrm{~min}$. (5 $\mu \mathrm{m})$.

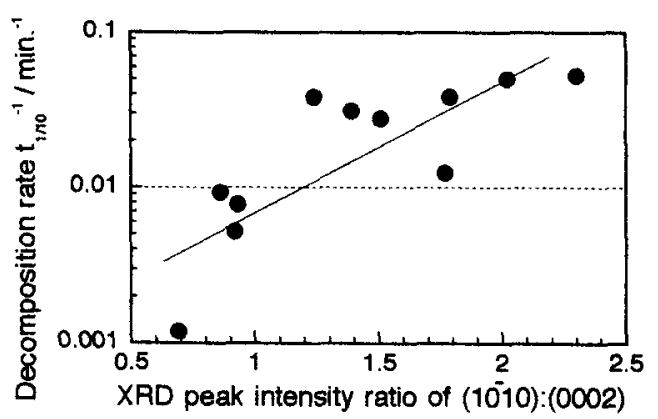

Fig. 8 Relationship between decomposition rate and $X R D$ peak intensity ratio of (1010):(0002) for the films prepared under cooling. 
(1010) to (0002) (Fig. 8). These results suggested that the decomposition rate was higher as the ratio $(10 \overline{10}):(0002)$ increased.

In addition, we studied the relationship between the decomposition rate and the ratio $(10 \overline{10}):$ (0002), regarding to the white and transparent films under the same condition except for temperature (Fig. 9). This result shows that keeping the electrolyte at low temperature tends to make preferred orientation of (1010) face, and improve the photocatalytic activity.

At a atomic level, the (1010) face consists of oxygen-zinc-oxygen alternating atomic layer, while, the (0001) face consists of monotonous oxygen atomic layer. It was reported that the surface zinc-oxygen combination played a

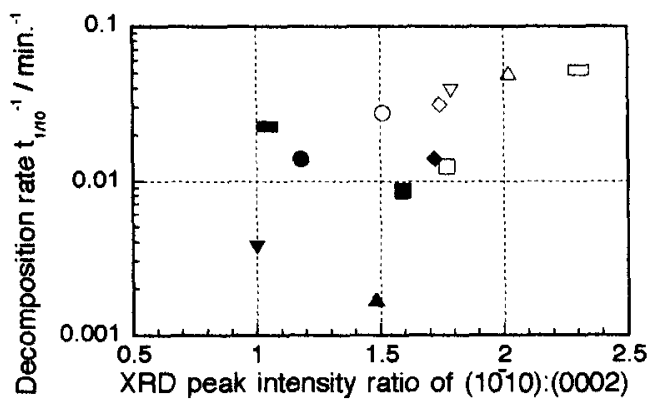

Fig. 9 Relationship between decomposition rates and $X R D$ peak intensity ratios of (1010):(0002) for the white and transparent films; closed and open marks denote the plots for the film prepared under no cooling (white) and cooling (transparent) respectively.

O: $0.1 \mathrm{~mol} \mathrm{dm}_{-3}^{-3} \mathrm{NaOH}, 20 \mathrm{VDC}$

$\diamond: 0.1 \mathrm{~mol} \mathrm{dm}^{-3} \mathrm{NaOH}, 30 \mathrm{~V} \mathrm{DC}$

$\Delta \triangle: 0.2 \mathrm{~mol} \mathrm{dm}_{-3}^{-3} \mathrm{NaOH}, 20 \mathrm{VDC}$

$\nabla \nabla: 0.2 \mathrm{~mol} \mathrm{dm}^{-3} \mathrm{NaOH}, 30 \mathrm{VDC}$

口: $0.3 \mathrm{~mol} \mathrm{dm}_{-3}^{-3} \mathrm{NaOH}, 20 \mathrm{~V} \mathrm{DC}$

$\square: 0.3 \mathrm{~mol} \mathrm{dm}^{-3} \mathrm{NaOH}, 30 \mathrm{VDC}$ important role for catalytic reactions 9) So such a catalytic characteristics for (1010) face would make the superior photocatalytic activities. In addition, the illuminated light would permeate deeply into the transparent film, and some of excited electron thole pairs could migrate to the surface and participate in the surface reaction.

In conclusion, the transparent $\mathrm{ZnO}$ films could be formed by cooling the electrolyte $\left(<10^{\circ} \mathrm{C}\right)$ for anodizing zinc plate. Thus obtained film was uniform and showed preferred orientation of the

(1010), further, it showed good characteristics as a photocatalyst.

\section{References}

1) Y.Yamaguchi, M.Yamazaki and S. Yoshihara, T.Shirakashi, J. Electroanal. Chem. Interfacial Electrochem., 442, 1 (1998).

2) C.Kormann, D.Bahnemann and M. Hoffmann, J.Photochemistry and Photobiology A, 48, 161 (1989).

3) R.Draper and D.Crosby, Photochemistry of Environmental Aquatic Systems (ACS Syposium Series), Am. Chemical. Soc., p.240 (1987).

4) X.Domenech and J.Munoz, J. Chem. Tech. Biotechnol., 47, 101 (1990).

5) J.Domenech and J.Peral, Solar Energy, 41, 55 (1988).

6) Y.Yamaguchi, M. Yamazaki, S.Yoshihara and T.Shirakashi, Denki, Kagaku, 64, 373 (1996).

7) M.Izaki and T.Omi, J. Electrochem. Soc., 143, L53 (1996).

8) M.Izaki and T.Omi, J. Electrochem. Soc., 144, L3 (1997).

9) A.Ueno, T.Onishi and K.Tamaru, Trans. Faraday Soc., 67, 3585 (1971). 